\title{
FINES Y MEDIOS: UNA APROXIMACIÓN A LOS DERECHOS
}

\author{
«La tolerancia es ese molesto sen- \\ timiento de que tal vez, al fin de \\ cuentas, el otro pudiera tener ra- \\ zón».
}

(Anónimo)

\section{El dilema de los medios}

uele atribuirse a Maquiavelo haber dicho que el fin justifica los medios. Si no lo dijo por escrito, tal puede ser el resumen de sus ideas interpretadas por quien se empeñe en leer un consejo técnico en términos morales. El hecho es que, a partir del ilustre florentino, muchos políticos han sido acusados de maquiavelismo por emplear medios que la opinión pública rechaza. Y muchos de esos mismos críticos han repetido en privado aquella frase para explicar ante sus propios partidarios el empleo de medios dudosos en aras de algún propósito largamente anhelado.

En el común de las gentes existe sin embargo cierto consenso para sostener, en términos abstractos, que el fin no justifica los medios y que jamás debe emplearse un medio injusto, ni aun para perseguir un fin justo. Aunque tal afirmación no lleva por sí sola demasiado lejos a menos que se especifique qué medios y qué fines son justos o injustos, permite al menos identificar el meollo del problema: los fines injustos quedan fuera de su planteo, tanto como los medios justos. Lo que ocupa a los políticos y encrespa a los moralistas es la relación entre fin justo y medio injusto; o, para expresarlo de un modo más riguroso, el caso en que se dan las siguientes notas:

a) Un fin F que, desde una óptica moral E, es deseable ${ }^{1}$.

\footnotetext{
${ }^{1}$ En este caso prefiero hablar de óptica moral antes que de sistema moral,
} 
b) Un medio $\mathrm{M}$ que, desde la misma $\mathrm{E}$, es indeseable.

c) Un estado de cosas tal que F no puede lograrse sino con el empleo de M.

En tales circunstancias puede dispararse la pregunta del millón, a saber: ¿es deseable, desde la óptica moral E, emplear M para lograr F?. El interrogante se presenta como un dilema, porque si lo respondemos afirmativamente aceptaremos lo indeseable (M) y si lo hacemos en forma negativa rechazaremos lo deseable (F). Y, siempre que el dilema se plantee en abstracto, estamos dispuestos a resolverlo a la manera de Alejandro frente al famoso nudo: hacemos de nuestra respuesta negativa un principio moral y rehusamos examinar los intrincados lazos con que los elementos del problema se hallan vinculados.

\section{En la cancha se ven los pingos}

Es verdad: todos somos antimaquiavelistas cuando se trata de reflexionar acerca del funcionamiento de la óptica moral de cualquiera y siempre que no estemos hablando de medios concretos y de fines concretos. En la vida cotidiana, es común que nos mostremos

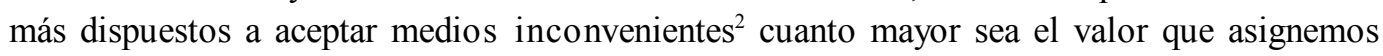
al fin que esperamos lograr con su empleo.

En este punto hacen su aparición ciertas complicaciones subjetivas en la apreciación del valor de fines y medios, cuya justicia o injusticia nos parece tanto menos importante cuanto más ajenos sean el perjuicio a evitar o la ventaja a obtener. Pero, aun dejando de lado esta consideración y situándonos en el punto de vista de

precisamente por la vaguedad de la primera expresión. «Sistema moral» evoca un conjunto de normas ordenadas jerárquicamente y dotado, al menos, de consistencia. Las ideas morales que los seres humanos suelen invocar (y, en casos extremos, incluso aplicar) en la vida real son a menudo conflictivas entre sí y sus vínculos jerárquicos se hallan sujetos a numerosas insubordinaciones, golpes de estado y eventuales restauraciones en las que no es raro que todo vuelva a su cauce para que algo permanezca modificado. Una óptica moral está entendida aquí como la situación en que se encuentra un individuo en un momento dado, o -por extensión- un grupo dado, suficientemente homogéneo para ser tomado aproximadamente como una unidad moral, en un lapso suficientemente breve como para que pueda suponerse que no ha habido modificaciones importantes en sus puntos de vista compartidos.

${ }^{2}$ En este caso los llamamos medios alternativos, heterodoxos, inevitables, heroicos o de cualquier otra manera persuasiva. 
un individuo personalmente desinteresado, la reflexión moral concreta no se nos presenta desprovista de paradojas.

Una de ellas, que vale como agudo ejemplo de una problemática más general, es la resumida en el conocido ejemplo del terrorista. Un individuo ha puesto una bomba en una escuela llena de niños, a quienes por algún motivo no es posible evacuar. El artefacto -según se ha anunciado- estallará dentro de media hora. El autor del atentado ha sido detenido y reconoce el hecho, pero se niega a informar dónde ha ocultado el explosivo. Si este dato no se obtiene dentro de los próximos quince minutos, sera imposible desarmar la bomba y centenares de niños morirán. ¿Es moralmente lícito torturar al detenido para arrancarle esa vital información?

Frente a tal hipótesis, nuestra conciencia moral se ve tironeada de mala manera. En nuestro interior, dos personajes mantienen un tenso diálogo:

-¡Jamás! Un ser humano no debe ser torturado por ningún motivo, aunque sea culpable de los más horribles crímenes.

-Sí, yo no aprobaría la tortura, pero en este caso se trata de la vida de centenares de niños inocentes. ¿No vale eso más que la integridad del terrorista?

-Desde luego; pero no más que el principio de respeto por los derechos individuales.

- ¿Y los derechos individuales de quienes serían condenados a morir por nuestra inacción? Tengamos en cuenta que ellos son muchos y son inocentes, mientras el detenido es uno solo y es culpable.

-Es verdad; pero razonar de esa manera nos llevaría a justificar muchas iniquidades que la humanidad considera superadas, incluidas algunas muy cercanas en el espacio y en el tiempo. ¿Acaso hemos de adherir a la tesis de «por algo sería»?

El debate podría continuar hasta después del estallido, sin que los dos cuernos del dilema llegasen a coincidir. Lo curioso es que cada uno de los personajes en debate tiende a estimar que tanto su propia posición como su relativa (y conflictiva) aceptación de la tesis opuesta responden a una convicción moral fuertemente arraigada en su conciencia, cuando todo parece indicar que al menos una de esas tesis tiene su base en una posición más pragmática que ideológica, emparentada con el escepticismo ético.

\section{El mundo es redondo}

En efecto, aproximémonos nuevamente al dilema y tratemos de hacerlo con espíritu ingenuo, desprovisto de preconceptos 
acerca de métodos o garantías. Si logramos hacerlo (y, por cierto, no estoy afirmando que ésta sea la forma correcta de abordar el tema), el dilema desaparece. En su lugar se nos presenta una simple comparación de valores, que hemos de juzgar de acuerdo con lo que aceptamos como nuestra escala axiológica. En este contexto es posible citar cuatro ideas morales que gozan de gran aceptación:

a) Una vida es muy valiosa, pero muchas vidas valen más que una sola.

b) La vida vale, en principio, más que la integridad física o la ausencia momentánea de dolor.

c) El inocente merece mayor protección que el culpable, cualquiera que sea el nivel de protección que se desee brindar a este último.

d) Los niños son siempre inocentes.

Si adherimos a estas ideas, la solución del problema moral aparece ante nuestros ojos como el resultado inevitable de una ecuación: no sólo es lícito torturar al detenido: es moralmente preciso hacerlo, con el mismo fervor con que adherimos al mal menor cuando abandonamos nuestra vivienda para huir de una inundación o adoptamos precauciones para no contraer el SIDA ${ }^{3}$.

¿Por qué, entonces, el problema nos parece desgarrador? ¿Por qué muchos de nosotros estamos dispuestos a dejar morir a los niños para impedir una tortura que juzgarnos abominable? Y, de paso, ¿por qué somos tan propensos a cambiar por completo de idea si entre los niños están nuestros propios hijos?

Hay una sencilla respuesta para estos interrogantes, una respuesta encerrada en dos refranes de la sabiduría popular: el mundo es redondo y el miedo no es zonzo.

En efecto, el ejemplo del terrorista supone que nosotros, desafiados a resolverlo, nos hallamos en la capacidad de decidir qué ha de hacerse con la vida y la integridad de las personas involucradas. Tenemos nuestra escala de valores que nos permite decidir, al menos en la aproximación ingenua. Pero ¿es la misma escala del terrorista? No, seguramente. Desde luego, tendemos a pensar que él está «equivocado» y nosotros «en lo cierto». Lo pensamos

${ }^{3}$ La comparación más habitual es la de la operación que amputa una parte del cuerpo afectada de cáncer: la omito deliberadamente porque es demasiado cara al temperamento autoritario. Creo que, moral y políticamente hablando, en nuestra sociedad hay demasiados cirujanos, muy pocos buenos clínicos y una angustiosa escasez de higienistas. 
también ingenuamente, llevados por la fuerza autopersuasiva de un lenguaje marcadamente ontológico. O bien hemos reflexionado acerca del tema y adherimos a una teoría (utilitarista o intuicionista, por ejemplo) que nos permite hablar de verdades y falsedades éticas. Pero, aun en este caso ¿qué perspectivas tenemos de lograr que el terrorista advierta la corrección de nuestro razonamiento o perciba la intuición adecuada? La historia del mundo es un buen ejemplo de la limitada capacidad de los hombres para convencer a otros sin apelar a la conveniencia personal e inmediata de los interlocutores, a las desventajas artificiales (ad baculum) o a argumentos falaces (ad hominem).

Si no podemos confiar en nuestra capacidad de ganar adeptos a nuestra propia escala de valores, corremos el riesgo de que en otro momento sea el mismo terrorista (u otra persona que no coincida con nuestras intuiciones éticas) quien se encuentre en condiciones de decidir si debe torturarnos a nosotros para preservar lo que él considera un valor relevante. Llegado ese caso ¿estamos dispuestos a defendernos sobre la base de que nuestra escala es mejor que la de él? ¿No temeremos fracasar en tan temerario intento? Es más: ¿estamos seguros de tener siquiera la oportunidad de ensayar una argumentación?

Este sentimiento ha atenazado desde siempre la conciencia moral de los hombres. Como resultado han ido surgiendo por consenso, a lo largo de los siglos y no sin arduas luchas, algunas ideas limitativas acerca de los métodos a utilizar, cualquiera que sea el fin que se persiga. Tales limitaciones tienen por objeto preservar algunos bienes en general apreciados; pero para preservarlos es preciso ponerlos fuera del mercado axiológico, donde podrían sucumbir frente a un juicio de valor adverso, del mismo modo en que un inmueble constituido en bien de familia permanece ajeno a los vaivenes de fortuna de su propietario. Así, no se debe torturar a un individuo en circunstancia alguna; no se debe privar a alguien de su libertad ambulatoria por razones puramente subjetivas, aunque éstas nos parezcan correctas; no se debe impedir a la gente reunirse, opinar y comunicar sus ideas, aunque tales ideas se nos antojen abominables y aquellas reuniones inconvenientes. Estas garantías, cuyo paradigma son los derechos humanos, operan al modo de diques morales que contienen la acción en busca de ciertos fines y la encauzan de tal modo que esa acción, aun a riesgo de fracasar, evite lastimar ciertos intereses considerados fuera de los límites del disenso.

La fortaleza de esos límites tiene una medida: la del equilibrio entre nuestro ardor en la persecución de los fines y nuestro rechazo ante la eventualidad de sufrir ciertos medios (acompañado 
de nuestro juicio de probabilidad respecto de esa perspectiva). La incidencia del primer término de esta ecuación puede contribuir a explicar por qué personas habitualmente moderadas reclaman de pronto la pena de muerte para el miserable que les sustrajo el pasacasetes del automóvil. La del segundo término, por qué tendemos a defender con menor ahínco las garantías que no nos incumben y a ser más severos respecto de los hechos que no nos imaginamos capaces de cometer o de las personas o grupos de los que no imaginamos que lleguen jamás a situarse por encima de nosotros.

Si nos situamos en el plano colectivo, aquella ecuación sirve también para comprender por qué los fanatismos (o, como se dice ahora, los fundamentalismos) entrañan tanto peligro para la convivencia. El individuo que está absolutamente seguro de su escala de valores y supone que hay en ella una verdad evidente que sólo los ciegos y los perversos se niegan a ver puede coincidir acaso con el contenido de nuestras propias convicciones. Pero el énfasis que pone en ellas tiende a desbordar los diques que trabajosamente se han construido para dejar a salvo ciertos intereses más o menos comunes entre opiniones divergentes. Y, producido el desborde, ya nadie quedará a salvo de la inundación, cuya marcha depende del viento.

\section{Derechos humanos, sistema jurídico y «laissez faire»}

He mencionado algunos de los límites morales que habitualmente se invocan, aunque no me parece demostrado que ellos sean naturales ni que cada uno de ellos sea por sí solo necesario: muchas sociedades han existido con límites diferentes. Lo que puede afirmarse es que la ausencia de todo límite constituye al menos un excelente caldo de cultivo para el estrés. Hasta la mafia tiene cauces rigurosos para la persecución de los fines de sus miembros: sea cual fuere la enemistad entre dos mafiosos, la omertá prohíbe a cada uno de ellos denunciar al otro. Y, aunque está permitido asesinarse recíprocamente, la familia personal de ambos debe quedar a salvo. Las convenciones de Ginebra sobre prisioneros de guerra o los tratados que vedan el uso de ciertas armas se inscriben en un plano semejante.

Por cierto, tanto en la mafia como en las sociedades más ortodoxas, poner ciertos intereses fuera del mercado axiológico requiere en alguna medida el esfuerzo de endiosarlos, de integrarlos en una ideología para dejarlos a salvo del pragmatismo de cada momento y de cada persona. Y esta ideología debe ser tanto más 
poderosa cuanto más fuertes sean los fines sobre los cuales tenga que prevalecer; podemos dejar morir a centenares de niños para no torturar al terrorista, pero no lo haremos si en ese momento nos permitimos poner en la balanza los valores en juego en la coyuntura. Curiosamente, esta decisión requiere cierto contrafundamentalismo apoyado en los intereses generales (tales como se los entiende en una sociedad dada), una convicción que ha dejado atrás su base pragmática y eventualmente escéptica para parecerse, por su solidez, a la fuerza que se le opone. Una vez convertidos los límites en principios, sostenerlos contra una balanza valorativa coyunturalmente desfavorable es difícil; ponerlos en práctica contra un saldo axiológico fuertemente negativo es heroico; aceptarlos en conflicto con un interés personalísimo requiere el temple de un personaje de Corneille.

Sería un descuido, sin embargo, suponer que los límites, diques o umbrales a los que me he referido funcionan de este modo sólo en aspectos tan relevantes como el de los derechos humanos. En rigor, todos los derechos son «humanos» en tanto sus titulares y sus obligados correlativos son casi siempre ${ }^{4}$ miembros de nuestra especie y en cuanto tales derechos son siempre enunciados, invocados o rebatidos en el seno de alguna cultura humana. Pero llamamos derechos humanos a ciertas exigencias morales que gozan de consenso general en un momento dado y de las que son presuntos beneficiarios todos los seres humanos, por el solo hecho de serlo y con independencia de sus cualidades personales o de las culpas en que hayan incurrido o se les atribuyan; exigencias que -cuando son sostenidas como tales- no ceden ante ninguna consideración de necesidad, emergencia o guerra ${ }^{5}$.

Existen también otros umbrales más bajos, destinados a ser sobrepasados en ciertas circunstancias (delito, emergencia, guerra) o aplicados a cierta clase de personas (inocentes, mujeres, compatriotas, trabajadores, miembros de tal o cual profesión o grupo). Muchos de

${ }^{4} \mathrm{Al}$ decir «casi siempre», pienso en los derechos de los animales, si por tal cosa queremos entender el reflejo de la obligación de no maltratarlos, como diría Kelsen (Teoría Pura del Derecho, México, UNAM, 1981, pág. 140). Aunque ésta no es la acepción más prestigiosa desde el punto de vista jurídico, parece ser la más usual cuando se habla de derechos en sentido moral.

${ }^{5}$ Naturalmente, éste es uno de los conceptos de derechos humanos que es posible enunciar o definir, pero me parece el que mejor se adecúa al tipo de defensa que de tales derechos se hace. En el contexto de esta definición, una buena piedra de toque para el criterio de uso de la expresión es pensar que los derechos humanos son los derechos de mi peor enemigo. Si para respetarlos debo preguntar quién los vulnera o quién sufre su violación, o bien no se trata de estos derechos humanos o yo no soy un defensor leal de ellos. 
estos umbrales, de disímil altura y con los más variados 
campos de aplicación, se consideran suficientemente relevantes como para recogerlos en normas jurídicas ${ }^{6}$.

Es más: todo el sistema jurídico puede considerarse como un mecanismo destinado a recoger límites de este tipo y a otorgarles más fuerza motivadora. La organización legal y constitucional, la presencia de tribunales y policía, todo el complejo de derechos y obligaciones que emana de leyes, contratos, sentencias o circulares del Banco Central constituye una red de circuitos de medios, algunos de los cuales son obligatorios, otros prohibidos y otros facultativos. La declaración de la independencia de los Estados Unidos proclamó como derechos inalienables la vida, la libertad y la consecución de la felicidad ${ }^{7}$. Si conseguir la felicidad es utópico, perseguirla es humano. Por cierto, no está dicho en qué haya de consistir la felicidad para cada uno y, en todo caso, son numerosos los caminos que según diversos pareceres puedan acercarnos a ella. En otras palabras, pues, cada individuo persigue lo que entiende como sus propios fines por los medios que juzga conducentes. Pero en esa persecución hay vías que le está vedado recorrer: no puede resolver sus problemas sentimentales matando a su cónyuge, ni agregar una habitación a su vivienda invadiendo la del vecino, ni incrementar la rentabilidad de su negocio omitiendo el pago de impuestos o abonando salarios inferiores a los establecidos, ni asegurarse el respeto y la obediencia de sus hijos mediante mutilaciones o castigos crueles, ni divertirse en sus fiestas causando ruidos molestos, ni llegar puntualmente a sus compromisos estacionando el automóvil en doble hilera. Todos esos fines son lícitos, pero sólo pueden perseguirse por medios no prohibidos, cualquiera que sea el juicio del interesado acerca de la mayor eficacia de alguno de los medios vedados respecto de los permitidos; y las restricciones se imponen por una vía ajena a la ética porque no es posible confiar, no ya en la fuerza de voluntad de los infractores potenciales (en especial frente a balances valorativos coyunturales e individuales opuestos a la restricción), sino incluso en el acuerdo unánime respecto de la inconveniencia de tales medios.

Los medios permitidos, en cambio, constituyen el reino del laissez faire. Cuando los tenemos a nuestro alcance preferimos no renunciar a ellos, en especial cuanto menores

\footnotetext{
${ }^{6}$ Es decir, los legisladores los consideran suficientemente relevantes para erigirlos en normas positivas respaldadas por sanciones socialmente organizadas.

${ }^{7}$ Cfr. Heffner, Richard D., Historia documental de los Estados Unidos. Buenos Aires, Arayú, 1955 , pág. 6.
} 
sean nuestras razones para temer que otros los empleen de un modo que nos perjudique. 
Así, es probable que el funcionario que puede designar por su sola voluntad a un pariente o amigo en un cargo público se niegue a aceptar el sistema de concursos (aun cuando de hecho no emplee aquella facultad o haga de ella un uso criterioso), y quien dispone del poder de fijar precios reclame la libertad del mercado.

\section{Los medios y las formas de gobierno}

Naturalmente, la proscripción de unos medios y la permisión de otros requiere el ejercicio de poder. Es más: podríamos atrevernos a afirmar que el ejercicio del poder consiste precisamente en eso. Y, desde luego, quien ejerce el poder también persigue sus propios fines (colectivos o políticos, incluidos en un programa explícito o implícito de gobierno, e individuales, como el goce del mando, el aprecio de los súbditos, el reconocimiento de la historia, la reelección o el enriquecimiento). La persecución de estos fines es tanto más fácil cuanto menores sean las restricciones impuestas a los medios capaces de conducir a ellos; y esta reflexión conduce insensiblemente en dirección al absolutismo: casi todo gobernante juzga insuficiente su propio poder y se queja, aunque sea en privado, de los límites que se oponen a su ejercicio.

Maquiavelo fomentaría sin duda esa tendencia, pero su aprobación iría acompañada por una grave advertencia al príncipe: si el poder ha de ejercerse ilimitadamente, es preciso asegurarse de no perderlo jamás... o de huir a tiempo. A despecho de la geografía, hay que construir un mundo perfectamente plano que no amenace aplastarnos en una de sus vueltas. Si esto no es posible (y ya no lo es desde que se descubrió que la cabeza de Luis XVI sí era redonda), tal vez sea preferible negociar algunas restricciones al poder político para que todos vivamos más tranquilos. ¿Cuáles restricciones? Con esta pregunta, el problema se traslada a otro nivel.

La democracia es el sistema que se ha hallado para responder de modo más o menos flexible a ese interrogante. No sólo abre a todos las expectativas de ejercer el poder (estableciendo para ello medios convencionales de llegar al gobierno): suele fijar, además, ciertas restricciones mínimas a la capacidad legislativa (las garantías) y algunos mecanismos para que, aun dentro del marco de estas garantías, la proscripción o la liberación jurídicas de los medios para perseguir los fines de cada uno se ajusten en lo posible a la expresión institucionalizada de cierto consenso (el Parlamento y otros órganos colectivos).

La Constitución argentina de 1853 -por señalar el ejemplo 
más cercano- ha tomado cuidadosamente en cuenta la necesidad de evitar las acumulaciones de poder que no tengan a su alrededor otras acumulaciones capaces de controlarlas. Así, el presidente no puede desafiar la autoridad del Congreso; la acción de ambos es controlada en sus efectos individuales y concretos por el Poder Judicial, que no obstante se halla obligado a aplicar normas en cuya redacción no participa, y los jueces son elegidos por el Poder Ejecutivo y destituidos por el Senado, sin perjuicio de su derecho de defensa. A esto se agrega una sabia previsión, que no siempre es apreciada en todo su valor: el presidente, los senadores y los diputados son electos por distintos períodos y los jueces son en principio inamovibles, lo que asegura una frecuente expresión de la voluntad de los electores y -a la vez- un fraccionamiento en el tiempo de los efectos de esa voluntad, de tal modo que un vuelco brusco de la opinión pública sólo produce un efecto limitado, a menos que se mantenga por algún tiempo. Sancionada en su momento por personas que deseaban fuertemente prevenir el despotismo, la Constitución trata de erigirse en una valla para quien desee perseguir sus fines (justos o injustos) por medios que la comunidad ha juzgado históricamente peligrosos o que afecten intereses dotados de consenso. Por esto ha sido tan común en nuestra historia que diversos grupos hayan tratado de eliminarla, suspenderla, sustituirla o, más modestamente, utilizar sus resquicios.

\section{Conclusiones}

Lo que he expuesto hasta aquí no pretende, por cierto, afirmar con efecto universal que el fin justifica los medios ni lo contrario. Tampoco comporta la ilusión de demostrar a quien no quiera ser convencido que los derechos humanos deben ser respetados, que la democracia es la mejor forma de gobierno ni que unas restricciones son mejores que otras. La tesis sustentada podría resumirse en las siguientes proposiciones:

a) El problema de los medios y los fines puede resolverse en un simple cálculo comparativo a condición de que se parta de una única escala de valores y que la solución se considere válida sólo para la óptica moral que contiene dicha escala.

b) Si a pesar de ello subsiste, su permanencia se debe a que tenemos conciencia de dos circunstancias: (i) que no existe un método intersubjetivo dotado de aceptación general para resolver las controversias éticas (idea que se mueve naturalmente en el 
contexto de la teoría emotivista, provoca una crispada frustración en el intuicionismo y suscita cierta esperanzada docencia en el naturalismo), y (ii) que, sean cuales fueren nuestra teoría ética y nuestra posición moral, como consecuencia de lo anterior es preciso prevenir el uso por terceros de medios que no estamos dispuestos a padecer.

c) Por lo tanto, los hombres se esfuerzan por alcanzar ciertos acuerdos interescalas, para que, por encima de las escalas de valores que cada persona o grupo sustente, algunos intereses que se suponen comunes no sean afectados más allá de lo tolerable. Estas restricciones funcionan como límites de disenso moral y, aunque de hecho se hallan también sujetas a controversia, su aceptación más general las eleva ideológicamente a la categoría de principios.

ch) Los problemas no terminan allí, ya que subsisten dos inconvenientes: (i) no se puede confiar en la aceptación unánime de tales principios, ya que quien no los comparta no puede ser persuadido racionalmente si su disenso es profundo; y (ii) aun respecto de quienes los comparten en abstracto, no existe garantía alguna del juicio de cada individuo en una coyuntura que lo afecte personalmente, con lo que el balance axiológico del caso concreto resulte desfavorable al principio sustentado.

d) Por este motivo se juzga generalmente necesario dotar a algunos de esos principios de una garantía adicional, como su recepción en un sistema jurídico respaldado por sanciones.

e) En rigor, todo el sistema jurídico aparece destinado a respaldar de este modo las restricciones que se busca imponer a los medios con los que cada uno persigue sus propios fines. El precio de esta garantía se traduce en que es quien ejerce el gobierno el que decide, de hecho, aquellas restricciones, cuyo resultado puede no coincidir con el consenso real de la sociedad.

f) Con el tiempo, esta falta de coincidencia llegó a ser experimentada como nociva por amplios sectores que adquirieron poder. Para evitarla, muchos promovieron el sistema democrático de gobierno, donde los fines del gobernante se suponen sujetos en alguna medida a la voluntad de los electores y donde los medios se hallan en parte limitados por las garantías constitucionales y en parte controlados por un sistema de frenos y contrapesos que deriva de la división de poderes.

g) A esta estructura suelen oponerse, con éxito variable, (i) los grupos fundamentalistas, que por considerarse absolutamente seguros de sus propias escalas de valores y por juzgar sencillamente erróneas o perversas las que a ellas se oponen, no están dispuestos a aceptar restricciones interescalas y juzgan cada situación mediante 
un balance axiológico puramente interno; y (ii) quienes en cada momento ejercen funciones de poder (político, económico o de cualquier otra naturaleza) y, por considerarse en condiciones de lograr sus fines, desean en mayor o menor medida trascender los límites que se oponen a los medios que estiman conducentes. 